\title{
Calibration of soil humidity sensors of automatic irrigation controller
}

\author{
Akhmet H. Abdelfattah, Rais F. Sabirov, Boris L. Ivanov, Maxim A. Lushnov, and Raushan A. Sabirov* \\ Kazan State Agrarian University, 420015 Kazan, Russia
}

\begin{abstract}
The article discusses the issues of increasing the efficiency of irrigation of crops cultivated in agriculture. Precise irrigation is an effective solution to irrigation problems. The methods and means of intellectual irrigation, based on sensors that monitor soil moisture and provide signals to the irrigation control solenoid valve, are described. A block diagram of an automatic drip irrigation system is described. For the experiment, five different types of droppers (A, B, C, D, and E) were used Rivulis Eurodrip brand, three of which are droppers with pressure compensation and two are the droppers without pressure compensation. Three parameters were used to study the characteristics of droppers: flow uniformity; volumetric water flow depending on the inlet pressure; determination of the dropper constant and the volume flow exponent. Droppers were tested at three pressures in the system: 0.05, 0.2 and 0.35 MPa. At each pressure value, the experiment was performed in triplicate. The process of calibrating humidity sensors is described. An analysis is made of the effect of soil moisture on the electrical resistance of the sensor for various types of soils. It is recommended that moisture sensors be calibrated to local soil and water conditions.
\end{abstract}

\section{Introduction}

One of the current issues of agriculture is energy conservation as a complex task that agricultural enterprises can solve in various ways. One of the main factors ensuring the stability of agricultural production and food security is irrigated land. An essential reserve for improving irrigation efficiency is the improvement of the operational planning of irrigation using mathematical models and computer technology. The use of mathematical models and computer technology provides an increase in the efficiency of irrigation and drainage systems, reduction of water losses for filtration and surface runoff, environmental safety of the environment, and resource conservation.

Planning and operational management of irrigation are defined as the frequency of supply and volume of water supplied during irrigation. There are various approaches to the irrigation system, which are based on approaches that take into account water balance, soil moisture measurements, plant stress, and other factors. Scientific and technical planning and management of irrigation saves water, protects the plant from water stress, prevents leaching of fertilizers, and saves energy costs.

When managing irrigation, it is necessary to maintain soil moisture within an optimal range. The optimal range of soil moisture provides the planned productivity of agrocenoses, as well as the economical use of water, material, technical, energy, and information resources.
Today, agriculture is the largest consumer of freshwater. Water supply to agriculture is carried out from rivers, lakes, and aquifers up to $70 \%$. Note that in some developing countries this figure reaches $90 \%$.

Continued population growth in developing countries leads to an increase in demand for food and animal feed, which leads to an extensive expansion of irrigated land. The main task of modern agriculture is to establish underground drip irrigation, which produces more food with less water and energy. Therefore, the search for technologies to save water in irrigated agriculture is relevant.

In today's world, precision irrigation is a new concept of irrigation. Precise irrigation involves the use of water to meet the specific requirements of individual plants or management units and to minimize the adverse environmental impact of agriculture. A standard definition of precision irrigation is sustainable water management, which includes delivering water to plants at the right time, in the right amount, in the right place, and in the right order.

This technology allows controlling the variability of water in the field, which, in turn, increases the productivity and productivity of plants and the efficiency of water use, along with reducing energy costs for irrigation. Water savings of up to $25 \%$ are possible by increasing the efficiency of the application obtained using spatially diverse irrigation systems [1-5].

Connecting a soil moisture sensor to a simple relay or microcontroller turn this mechanism into a smart and intelligent irrigation controller that monitors irrigation

* Corresponding author: agromehanika116@gmail.com 
cycles and takes into account the wet condition of the soil, for example, after recent rain.

\section{Materials and methods}

The core element of an intelligent irrigation management system is the sensor. Sensors are an element of technical systems designed to measure, signal, regulate, control devices, or processes. Sensors transform the controlled value into a signal convenient for measuring, transmitting, converting, storing, and recording information about the state of the measurement object. Values are controlled overpressure, temperature, flow rate, concentration, frequency, speed, displacement, voltage, electric current. The received signal can be electric, optical, pneumatic signal [6-8].

The automatic soil moisture control module based on soil moisture sensors is shown in Figures 1 and 2. The circuit board consists of a $12 \mathrm{~V} 1$ relay, potentiometer 2 , power indicator 3 , digital switch 4 output, sensor 5 input, $\mathrm{DC} 6$ input, alternating current $\mathrm{AC} / \mathrm{DC} \pm 7$. The module operates on a supply voltage of $12 \mathrm{~V} \mathrm{DC}$ and an input current $>100 \mathrm{~mA}$ and is applied as a switching sensor for devices in an electrical load of $250 \mathrm{~V} 10 \mathrm{~A} \mathrm{AC}$ or $30 \mathrm{~V}$ 10 A DC.

The sensitive element consists of two open electrodes since the physical principle is applied here, according to which the mineral substances of the soil act as insulators. Dry soils have ultra-high electrical resistance, and the more water is contained in the soil, the lower the resistance between the two electrodes. The degree of electrical conductivity of the soil is primarily associated with the amount of any free moisture in the soil and dissolved salts. Sensor calibration was carried out for different soils and different irrigation waters.

Soil moisture can be regulated in a wide range, and the corresponding threshold value is regulated using potentiometric control. Clockwise adjustment is applied to increase the threshold value and counterclockwise to decrease the threshold value.

Indirect methods for determining soil moisture should be calibrated before use for specific soil conditions. Typically, some general calibration equations are provided by the manufacturer for mineral and organic soil.

However, for more accurate measurements, calibration is recommended for a specific soil. Using the well-known calibration equation, you can determine the volumetric moisture content in the soil for any sensor reading (ohm $/ \mathrm{mV}$ ) and adjust the threshold value to the desired soil moisture level.

When the moisture content in the soil is lower than the set value, the relay is activated. When the soil moisture reaches the required value, the relay automatically turns off, and watering stops. If there is insufficient soil moisture, the relay switches on the pump, and the green indicator lights up.

After irrigation and when the optimum moisture level is reached, the relay switches off the pump and, therefore, the green LED turns off. Figures 3 and 4 show a diagram of the controls for automatic drip irrigation using humidity sensors and a block diagram of the operation of the automatic drip irrigation system.

Calibration allows configuring the sensor for any soil moisture as a threshold value.

We use a soil moisture sensor, model HL 69. This model is an electrical resistance sensor. Its output is the electrical resistance in the soil between the two probes. The value of soil resistance decreases with increasing water content. Higher moisture content in the soil $(40.5 \%)$ gives a sensor output signal of 25, 28 Oand 20 Ohms for sensors 1, 2, and 3, respectively. A lower moisture content (14\%) gave the sensor output signal of 110113 and 103 Ohms for sensors 1, 2, and 3, respectively.

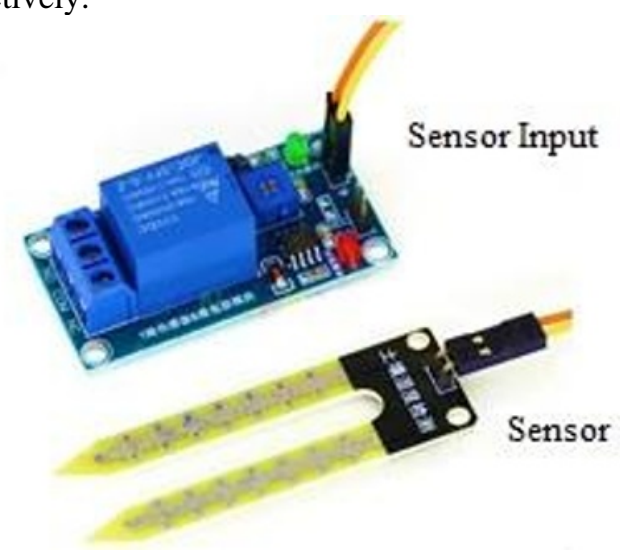

Fig. 1. Module for automatic control of soil moisture based on soil moisture sensors

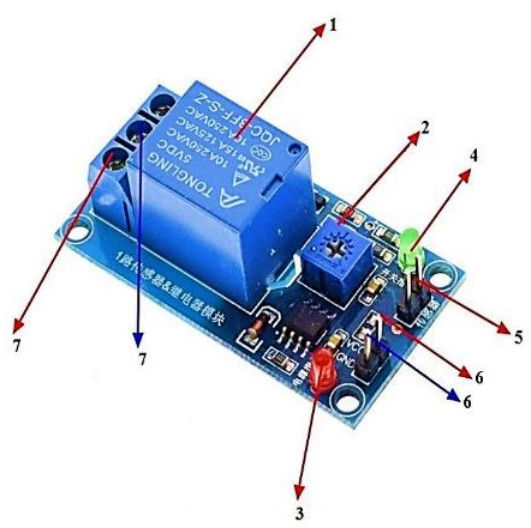

Fig. 2. Components of a circuit board of an automatic irrigation controller based on soil moisture sensors 


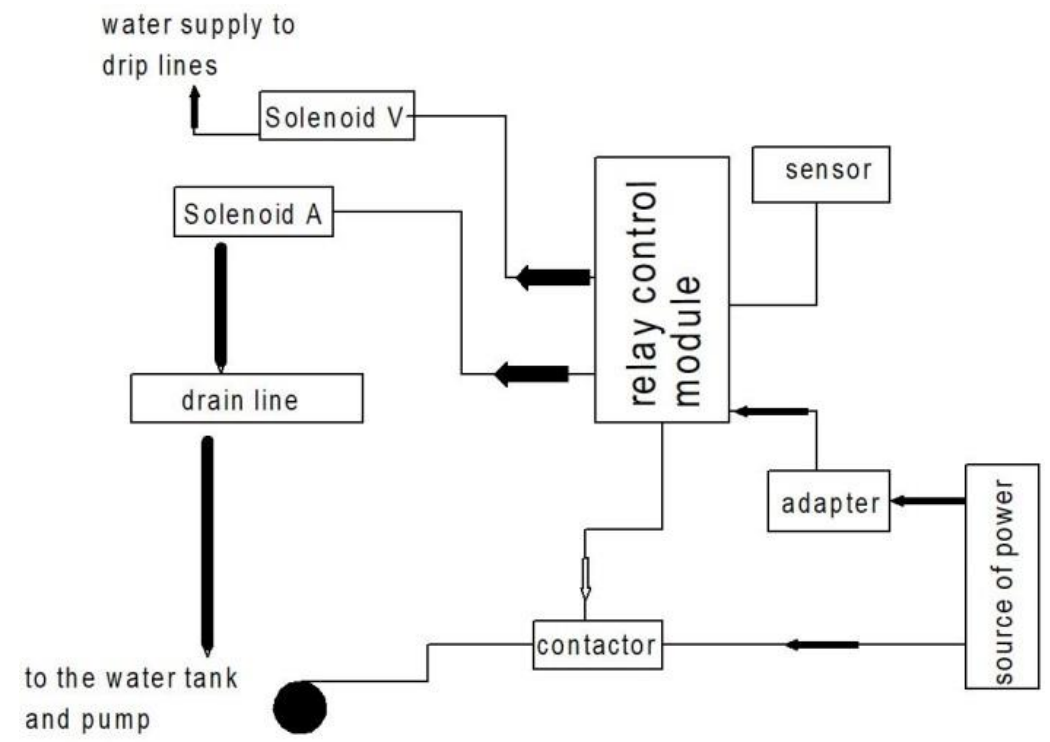

Fig. 3. Diagram of controls for automatic drip irrigation using humidity sensors

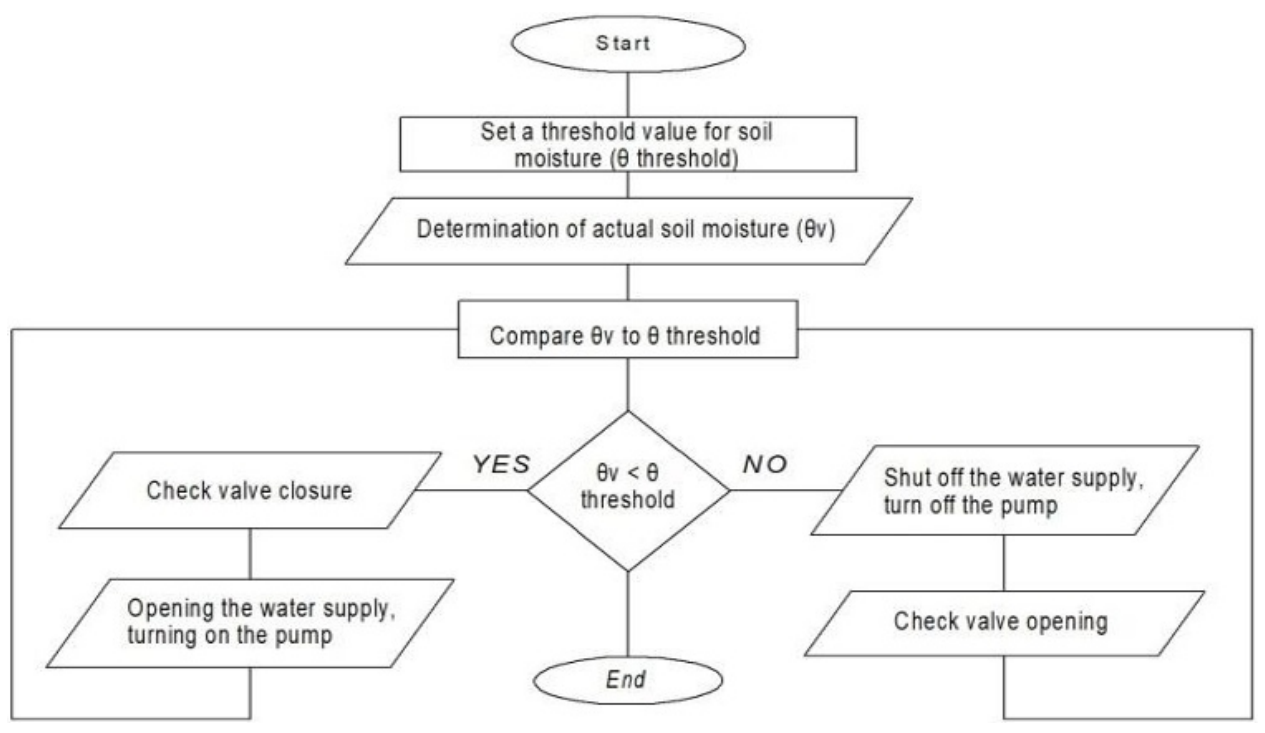

Fig. 4. Block diagram of the operation of an automatic drip irrigation system

Five different dropper types Rivulis Eurodrip brand (A, B, C, D, and E) were selected for the experiment. Three of the selected droppers are pressure compensated droppers. Two of the selected droppers are droppers without pressure compensation.

Three parameters were applied to study the characteristics of droppers. The first parameter is the flow uniformity. The second parameter is the volumetric flow rate of water, depending on the inlet pressure. The third parameter is the determination of the dropper constant and the volume flow exponent.

Droppers were tested at three pressures in the system: $0.05,0.2$, and $0.35 \mathrm{MPa}$. At each pressure value, the experiment performed in triplicate. After research, droppers were selected that showed the best uniformity of water distribution. The droppers selected as a result of this experiment were included in the automation process.

The operability of the irrigation system under production conditions tested in the greenhouse complex of Kazan State Agrarian University. According to the results of a study of accurate drip irrigation under production conditions, it was found that when using droppers $\mathrm{A}, \mathrm{B}$, and $\mathrm{C}$, the average green mass of the plant was $15,15.5$ and 18 ha, and the average weight of root crops was $10.3,10.8$ and $12.6 \mathrm{~g}$.

According to the calculation of the efficiency of water use, droppers of type $\mathrm{A}, \mathrm{B}$, and $\mathrm{C}$ for root crops amounted to $85.8,90$, and $109.6 \mathrm{~g} / \mathrm{l}$, and for the total biomass of the plant - 125, 129 and $156.5 \mathrm{~g} / \mathrm{l}$.

The calibration process of soil moisture sensors was as follows.

Soil samples were dried, distributing them on a paper substrate in the laboratory (Fig. 5). Stones, roots, or other unwanted materials were removed, and large clumps of soil were broken. Periodically, the soil was turned upside down or mixed, and drying occurred uniformly throughout the sample. Air drying of the soil can take from several days to several weeks, depending on the initial moisture content in the soil and how dry/hot the air is in the laboratory.

After the soil became dry enough, it was put in plastic containers that were deep enough to 
accommodate the entire length of the soil moisture sensor. The soil moisture sensors used were $5 \mathrm{~cm}$ long. According to [Barradas et al. 2014], 3 plastic containers with 3 different moisture levels are sufficient, but preferably, the more containers, the more accurate the calibration. In our experience, 10 plastic containers used for calibration $[6,9,10]$.

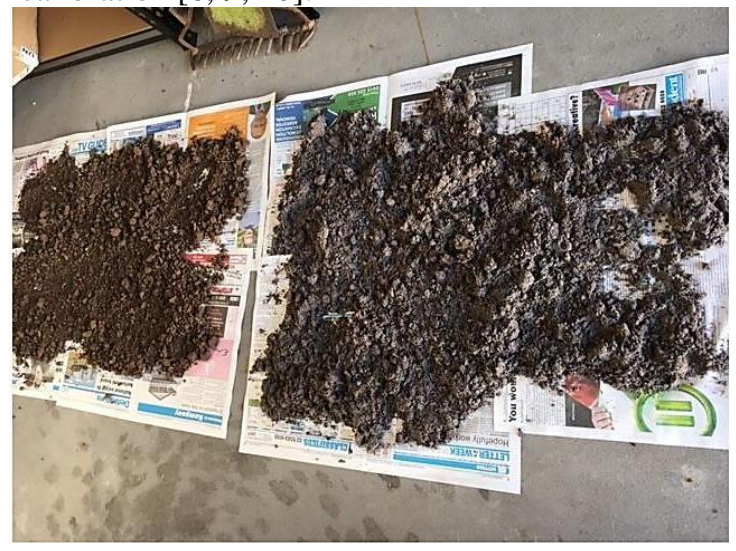

Fig. 5. Air drying of soil samples

After filling the plastic containers with soil, a moisture spectrum was in all containers. The first container marked as an air-dried sample, and the humidity gradually increased in other containers until saturated. Figure 6 shows that the soil moisture ranges from very dry to very wet. The corresponding values of the soil moisture sensors for various moisture levels were recorded using an ampervoltmeter. The same procedure can be repeated using different types of soil or irrigation water.

After recoding millivolts $(\mathrm{mV})$ or electrical resistance values measured by the sensors, part of the soil from each container was removed and weighed on the balance, and the wet weight was recorded. After part of the soil from all containers was weighed, they were placed in an oven set at $105{ }^{\circ} \mathrm{C}$ until a constant weight was achieved. Dry weight was recorded, and volumetric water content was calculated. A relationship was established between the volumetric water content in the soil and the sensor readings in ohms (or $\mathrm{mV}$ ). Calibration allows configuring the sensor for any soil moisture as a threshold value [11-13].

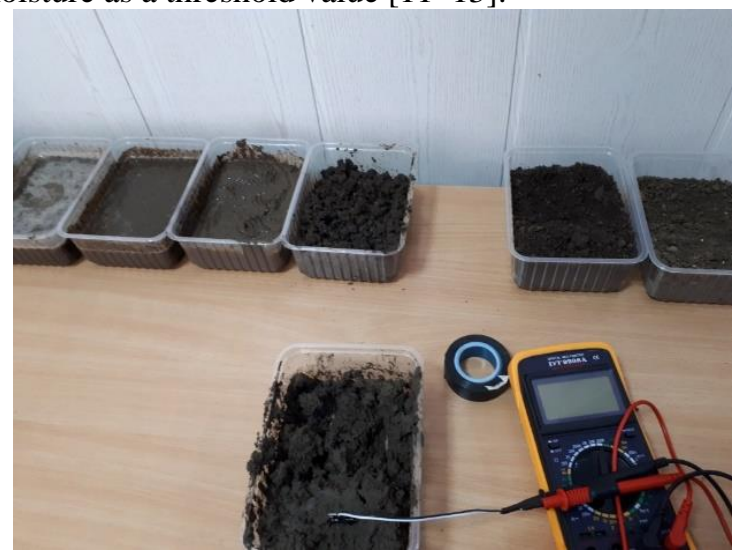

Fig. 6. Compiling a scale of soil moisture and connecting the sensor to an ohmmeter and recording the sensor output signal at different levels of soil moisture

\section{Results}

The soil moisture sensor was an electrical resistance sensor, model HL 69. Its output is the electrical resistance in the soil between the two probes. Figures 7 , 8 , and 9 show the obtained graphs for calibrating the three sensors. The value of soil resistance decreases with increasing water content.

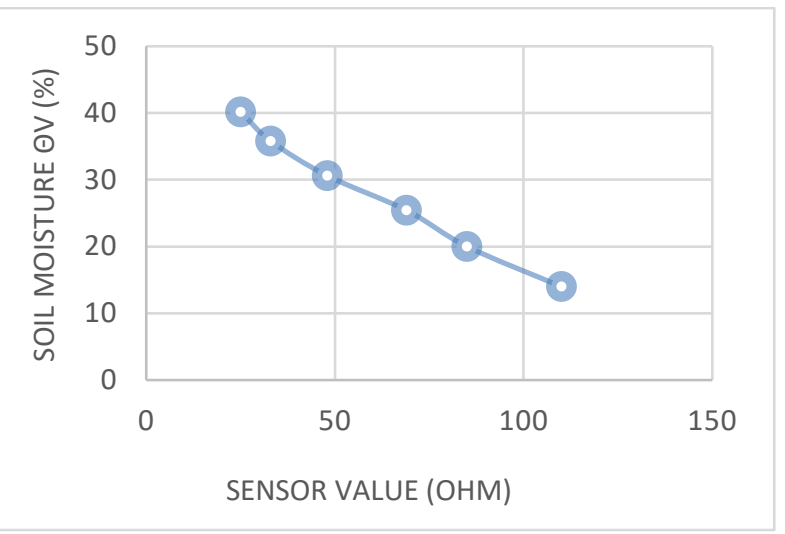

Fig. 7. Dependence of the readings of sensor № 1 on soil moisture

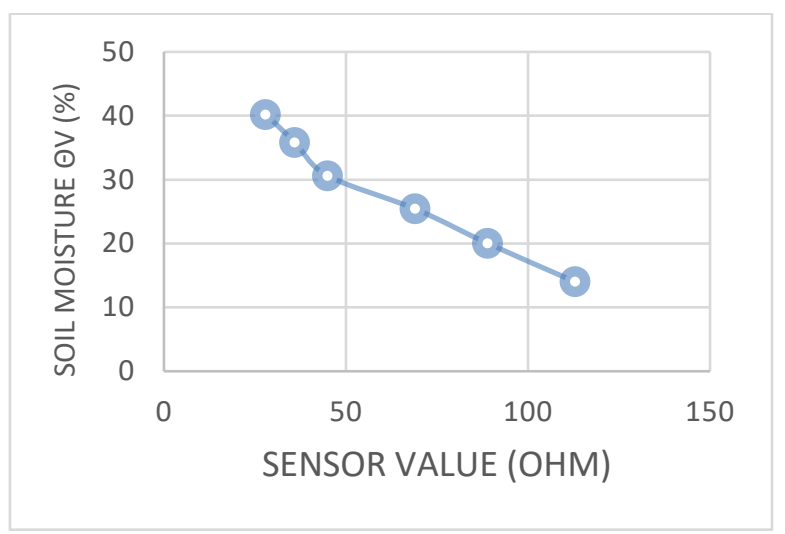

Fig. 8. The dependence of the readings of the sensor № 2 from soil moisture

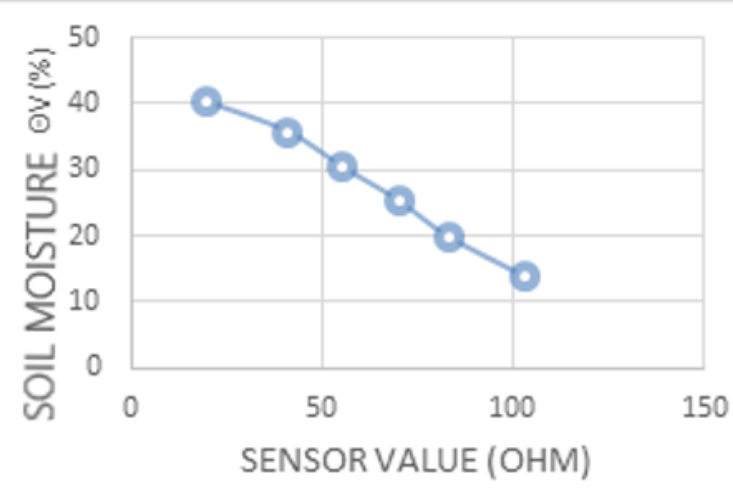

Fig. 9. The dependence of the values of the sensor No 3 on soil moisture

The graph is consistent with the data: since water is the only soil component that (1) has a high dielectric constant and (2) is the only component other than air that changes concentration, a dielectric sensitive device or 
electrical resistance can evaluate volumetric water content $[14,15]$.

The graphs show that a higher soil moisture content $(40.5 \%)$ gives a sensor output signal of $25 \mathrm{Ohms}$, $28 \mathrm{Ohms}$, and $20 \mathrm{Ohms}$ for sensors 1, 2, and 3, respectively. A lower moisture content $(14 \%)$ gave the sensor output signal of $110 \mathrm{Ohms}, 113 \mathrm{Ohms}$, and 103 Ohms for sensors 1,2 , and 3.

\section{Conclusion}

Based on the previous, to automate irrigation systems, it is recommended to calibrate the sensor to local soil and water conditions. The calibration procedure is applied to set the irrigation regulator to start and stop when the trigger point is reached. The trigger point is defined as the optimum moisture content in the soil for plants.

\section{References}

1. A.Kh. Abdelfattah, I.M. Gomaa, D.T. Khaliullin, Energy-efficient use of water resources in agriculture, in Proc. of the Regional sci.-pract. Conf. "Agroengineering science of the 21st century," 335-339 (Kazan State Agrarian University publishing house, Kazan, 2018)

2. A.Kh. Abdelfattah, D.T. Khaliullin, I.M. Gomaa, Management of soil irrigation using moisture sensors, in Mater. of the Int. sci.-pract. Conf. IMiTS "Current status, problems and prospects for the development of mechanization and technical service of the agro-industrial complex," 18-26 (Kazan State Agrarian University publishing house, Kazan, 2018)

3. A.Kh. Abdelfattah, B.G. Ziganshin, D.T. Khaliullin, I.M. Gomaa, Analysis of irrigation automation processes based on intelligent systems, in Mater. of the Int. sci.-pract. Conf. "Achievements of equipment and technologies in the agro-industrial complex," 13-21 (Publishing House of the Ulyanovsk State Agrarian University, Ulyanovsk, 2018)

4. I.I. Kashapov, A.A. Mustafin, B.G. Ziganshin, N.A. Korsakov, Energy-saving and energy efficiency. Development Prospects in Russia and the World, in Proc. of the Int. Sci. and Pract. Conf. "Agricultural Science of the XXI Century. Actual research and prospects," 175-181 (Kazan, 2015)
5. N.K. Mazitov, B.G. Ziganshin, A.R. Valiev et al., Energy-saving technologies and equipment for tillage and sowing in arid conditions, Bull. of Kazan SAU, 4(30), 65-75 (2013)

6. J.M. Moreira Barradas, A. Abdelfattah, S. Matula, F. Dolezal, Effect of Fertigation on Soil Salinization and Aggregate Stability, J. of Irrigat. and Drainage Engineer., Amer. Society of Civil Engin. (2014)

7. P. Munoth, R. Goyal, K. Tiwari, Sensor based irrigation system: A review, Int. J. of Engineering Research \& Technology, NCACE-2016 Conf. Proc., 4(23), 86-90 (2016)

8. T. Müller, C. Ranquet Bouleau, P. Perona, Optimizing drip irrigation for eggplant crops in semi-arid zones using evolving thresholds, Agricult. Water Managem., 177, 54-65 (2016)

9. M. Naderi-Boldaji, M. Younesi, A. Sharifi et al., A combined sensor for on-the-go measurement of soil water content and mechanical resistance: moisture sensor design and calibration, in 2nd Int. Conf. on Mach. Control and Guidance Proc., 163-170 (University of Bonn, Germany, 2010)

10. H. Sharma et al., Soil moisture sensor calibration, actual evapotranspiration, and crop coefficients for drip irrigated greenhouse chile peppers, Agric. Water Manag., 1-11 (2016)

11. Z. Jiang, C. Tan, X. Zhi, C. Wang, Y. Ma, Development of portable soil moisture detector based on principle of frequency domain reflectometry, Transd. Microsyst. Technol., 32, 79-82 (2013)

12. P. Mondal, V.K. Tewari, Present Status of Precision Farming: A Review, Int. J. Agricult. Res. (2007)

13. A. Ritter, C.M. Regalado, Corrections for Simultaneous Measurements of SoilWater Content and Salinity Using a Capacitance Sensor, In Proc. of the Annual Meet. on Amer. Society of Agricult. and Biolog. Engineers (2007 ASAE), 17-20 (Minneapolis, MN, USA, June 2007)

14. USDA (United States Department of Agriculture), Part 623 Irrigation National Engineering Handbook, chapter 7: Microirrigation, (USDA, Natural Resources Conservation Service, USA, 2013)

15. Y. Sun, P.S. Lammers, D. Ma, J. Lin, Q. Zeng, Determining soil physical properties by multi-sensor technique, Sens. Actuators, A 147, 352-357 (2008) 